\title{
'This place is not normal': mobile workers and HIVIAIDS
}

\section{Donna Bulman*}

University of New Brunswick, PO Box 4400, Fredericton,

New Brunswick, E3B 5A3, Canada

E-mail: dbulman@unb.ca

*Corresponding author

\section{Maria Mathews}

Division of Community Health \& Humanities,

Health Science Centre,

Memorial University of Newfoundland,

St. John's NL A1B 3V6, Canada

E-mail:mmathews@mun.ca

\section{Margaret Dykeman}

University of New Brunswick, P.O. Box 4400, Fredericton, New Brunswick, E3B 5A3, Canada

E-mail: margdyk@unb.ca

\section{Diana L. Gustafson}

Division of Community Health \& Humanities, Health Sciences Centre,

Memorial University of Newfoundland,

St. John's NL A1B 3V6, Canada

E-mail: diana.gustafson@med.mun.ca

\section{Fran Keough}

AIDS Committee of Newfoundland and Labrador,

47 Janeway Place, St. John's,

Newfoundland, A1A 1R7, Canada

E-mail: fkeough@acnl.net

\begin{abstract}
This qualitative research study explores lifestyle changes associated with mobile work that may put one at risk for acquiring HIV/AIDS or other STIs. Data collection occurred between 2008 and 2011. Sixteen men and women from Atlantic Canada participated. All participants had worked in the oil sands at Fort McMurray and had travelled back to Atlantic Canada at least
\end{abstract}


once in the year prior to data collection. Participants discussed lifestyle factors related to mobility and 'place' that might put them at risk for acquiring HIV/AIDS or other STIs. A thematic analysis was completed. Social disruption, the environment, workplace safety policies, and limited health services contributed to risky behaviours that could put participants at risk for acquiring HIV/AIDS or other STIs. Additional research, including ethnographic studies, is required prior to making recommendations to influence health promotion, harm reduction and occupational health and safety policies.

Keywords: mobile work and HIV/AIDS; place and HIV/AIDS; migration; mobile work; oil sands; internal migration; health risks; residential mobility.

Reference to this paper should be made as follows: Bulman, D., Mathews, M., Dykeman, M., Gustafson, D.L. and Keough, F. (2014) "This place is not normal': mobile workers and HIV/AIDS', Int. J. Migration and Residential Mobility, Vol. 1, No. 1, pp.72-83.

Biographical notes: Donna Bulman is an Assistant Professor at the University of New Brunswick. Her research interests focus on HIV, migration, chronic illness, and women's health.

Maria Mathews is a Professor of Health Policy/Health Care Delivery in the Division of Community Health \& Humanities in the Faculty of Medicine. She holds a $\mathrm{PhD}$ in Health Policy, Management, and Evaluation from the University of Toronto and a Masters in Health Services Administration from the University of Alberta.

Margaret Dykeman currently holds the position of Honorary Research Professor at the University of New Brunswick. She has extensive experience in the clinical fields of HIV, HCV, and addictions. She has been involved with a number of community based research projects based in both the USA and Canada.

Diana L. Gustafson is an Associate Professor of Social Science and Health in the Faculty of Medicine, Division of Community Health and Humanities and affiliate faculty in the Department of Gender Studies Program at Memorial University, Canada. Together these positions allow her to pursue her commitment to health-related social justice issues with a particular focus on marginalised populations.

Fran Keough has been working with AIDS Committee of Newfoundland and Labrador since 2005. She is currently the Harm Reduction Manager of this organisation.

\section{Introduction}

'This place is not normal' was how one Atlantic Canadian described the northern Alberta community where she lived. "Social norms and boundaries and just the way that people interact with each other and personal values and conversations and those sorts of things. It's a very different lifestyle". This woman was one of 15 participants in an exploratory study that investigated how the lifestyles of mobile workers who habitually travel between Atlantic Canada and the oil sands in northern Alberta may influence their 
vulnerability to Human Immunodeficiency Virus/Acquired Immune Deficiency Syndrome (HIV/AIDS).

Mobility is indirectly linked to the transmission of HIV and other sexually transmitted infections (STIs) internationally (Dodson and Crush, 2006; Quinn, 1994) and within the Canadian context (Goldenberg et al., 2008). The connection between mobility and HIV vulnerability is complex (Skeldon, 2000). Some of the factors that influence the health of mobile workers and thus the potential for acquiring HIV/AIDS are place of origin (Gushulak and MacPherson, 2011), destination community (Mendola, 2006), legal status (Davies et al., 2010), age at time of move (Saggurti et al., 2008) cultural norms (Saggurti et al., 2008), and gender issues (UNAIDS, 2008). Although internationally, literature related to HIV transmission and mobility is widely available, little qualitative research that explores the perspectives/experiences of mobile workers has occurred within the Atlantic Canadian context. This paper helps to address this gap in the literature.

\section{Background}

This research was carried out in New Brunswick, Newfoundland, and Labrador (NL) two provinces on the eastern seaboard of Atlantic Canada.

In 2011, New Brunswick had a population of approximately 751,232 (Statistics Canada, 2011) and the reported number of HIV positive test results between the years 1985 and 2008 were 365 (Public Health Agency of Canada, 2008). Additionally, between 2000 and 2008, the actual number of HIV cases in New Brunswick ranged from 6 to 16 cases with an average being 11 (Office of the Chief Medical Officer of Health, 2011). In NL the population was estimated at 509,148 (Statistics Canada, 2011) and between 1984 and 2010 there were 259 reported cases of HIV (Department of Health and Community Services, 2010).

Both New Brunswick and NL are primarily rural provinces. In New Brunswick, many young people have traditionally had to leave the province to find work. In NL, most outward migration occurs in people between the ages of 15-19 (Statistics Canada, 2010) and is related to economic and environmental restructuring which has negatively affected employment opportunities within NL (Dolan et al., 2005).

Many Canadians including those from New Brunswick and NL are attracted by jobs in the oil/gas sector (Ferguson, n.d.; Goldenberg et al., 2008). The oil sands underlie 140,200 square kilometres in northern Alberta in the areas of Athabasca, Cold Lake, and Peace River (Government of Alberta, 1995-2012). In 2010, approximately 140,000 people were employed in some aspect of this industry (Government of Alberta, 1995-2010). Athabasca Regional Issues Working Group (2007) made a conservative estimate that approximately 5,883 of the workers who commute come from Atlantic Canada.

It is difficult to get an accurate sense of the actual prevalence of HIV within the oil sands as many people who work there are temporary workers or internal migrants who may not necessarily be tested for HIV in either northern Alberta or their home location. There are many complex reasons for delaying HIV testing including confidentiality or privacy issues, work or camp location, legal concerns, discrimination and lack of awareness of associated risk factors. Additionally, due to recent changes in Alberta Health it is more difficult to obtain timely information about HIV/AIDS epidemiological data in Alberta (e-mail communication with Yamkowy, 2011, HIV North Society, 
December, 2011). However, the Government of Alberta (2011) reported 219 new cases of HIV in Alberta in 2009 of which $68 \%$ were men.

\section{Mobile workers and health risks}

Mobility is defined in this paper as "short term commuting involving at least one regular overnight stay from home in the course of income generation" [Saggurti et al., (2009), p.927]. According to this definition, people who go out to the oil sands to work for short periods and regularly commute between Atlanta Canada and northern Alberta would be considered mobile workers. Mobile workers, like people who migrate, are influenced by 'push' and 'pull factors' [Gushulak and MacPherson, (2011), p.1] such as poverty and job opportunities. Health risks associated with mobile work in the oil sands include those associated with 'rigger culture' [Goldenberg et al., (2008), p.352]. Rigger culture often involves hyper-masculinity, apathy towards self-care, and sexism (Goldenberg et al., 2008). This can result in health risks such as binging on alcohol or drugs, promiscuity, and increased rate of STIs/HIV (Health Canada, 2006). This is in addition to those health risks normally associated with geographic and social isolation such as depression, extreme loneliness, and lack of access to healthcare services.

\section{Research design}

This qualitative study explored lifestyle changes (that may put someone at risk for acquiring HIV/AIDS) that occur because of mobility between New Brunswick and NL and Fort McMurray, a resource extraction community in northern Alberta.

\section{Methods}

The data for this paper are from a qualitative exploratory study that examined lifestyle changes that occur due to engaging in mobile work. An advantage of this type of research is that researchers are able to describe events as they happen in real life (Merriam and Simpson, 2000). This study also incorporated some principles of community-based research including recognising the abilities and contributions of academic and community partners (Canadian Institutes of Health Research, 2011).

The study was approved by the ethics committees of Memorial University and University of New Brunswick. Members of the research team attempted to have the research study approved by a community-based ethics committee but at the time of data collection no such committees were operating in either New Brunswick or NL.

Participants were selected through purposive (Thorne, 2008) and snowball (Polit and Beck, 2009) sampling in order to achieve maximum variation (Sandelowski, 2000). Recruitment posters were placed in airports, truck stops, bus stops, pubs, social networking sites, and other community centres. We also did several media interviews to make people more aware of the study and to encourage recruitment.

Sixteen participants were recruited: nine from NL and seven from New Brunswick. Eleven were men and five were women, all between the ages of 24 and 63 years. All spoke English, and had travelled from either NL or New Brunswick to Fort McMurray at 
least once in the year prior to data collection. While in Alberta, participants were employed in fracking, counselling, and operating heavy equipment. They also worked as camp attendants, safety officers, and in a variety of technical positions. A number of participants lived in the work camps while others lived in hotels or other accommodations in Fort McMurray.

\section{Data collection}

Data were collected between 2008 and 2011. Each participant was interviewed once using a semi-structured interview guide developed in partnership with a community-based HIV/AIDS organisation. The guide was later refined to explore emerging themes including those that focused on socio-cultural and geographic factors that contributed to lifestyle choices. The interviews lasted approximately one hour and were carried out by either the principal investigator or a research assistant who worked out of the community-based AIDS Organization.

Participants were asked questions about rationale for deciding to find work in the oil sands in Alberta, migratory patterns, and life style changes that occurred as a result of migration. They were also asked about work patterns, drug use, sexual behaviour, health services, and general information about HIV/STI prevention activities. Interviews were audiotaped and transcribed verbatim.

\section{Data analysis}

A thematic analysis was completed. To ensure this process was rigorous the following activities occurred:

1 each interview transcript was checked for accuracy

2 a summary of each interview was written by the research assistant and reviewed by one of the PIs

3 micro coding was completed by research team members

4 the codes were combined into major themes and checked by a second individual

5 the data were rechecked to ensure the themes were inclusive of all data and that no forcing of data into themes had occurred

6 a preliminary draft of the findings was shared with our community partner for input

7 final findings were agree upon and contextualised at a meeting with our community partner.

\section{Findings}

This section presents findings under three thematic headings that relate to mobility between Atlantic Canada and the northern oil sands in Alberta: social disruption, 
environmental factors and limited health services. Other findings from the research will be discussed in forthcoming papers.

\subsection{Social disruption}

Social disruption is a situation that occurs when communities experience rapid growth and expansion resulting in a crisis that may influence individuals, communities and social groups (England and Albrecht, 1984; Park and Stokowski, 2009). This social disruption causes loss of routines and traditions. It may influence an individual's behavioural patterns. Social disruption may also affect mental health, social networks, relationships, and worldviews (England and Albrecht, 1984). Researchers suggest this phenomenon often occurs in 'boomtowns' (Summers and Branch, 1984). Parts of northern Alberta such as Fort McMurray and surrounding areas are often considered 'boomtowns'. One research participant described the social disruption that has occurred within Fort McMurray in the following words:
"They say [Fort McMurray] was such a beautiful little town. It was the same as any rural town in Alberta. You know, quaint. You could go out in the woods; you could go ski-doing. ... Then all of a sudden in comes all these migratory workers and the place is basically shot up. There are murders happening. There are drugs flying through the place... They [locals] feel like it's the migratory workers that have taken away their lifestyles."

Research participants described a sense of alienation and isolation from long-term residents of the area as well as from people living 'back home'. This contributed to the 'party culture' that occurs when visiting urban areas such Fort McMurray or Edmonton. This party culture occurred frequently when people were on a short period of time off and did not have time to return to their home town. One participant believed this happened as a way of dealing with the social and geographic isolation that occurred while living in a different location than family and friends.

"I've seen guys that I work with blow $\$ 500.00$ at a night club. I think certain guys have different ways that they kind of reconnect on their days off with other people. .... A lot of guys like to hit it [the bar] and [they] do that for four or five day's straight and then rest for a couple of days before they go out [again]."

Another participant stated "You drink more there.... because you have more time on your hands .... Your mobility is restricted". A second individual noted, "They say that prostitutes come here rather than anywhere else in Canada because the men are lonely and the men are rich". This participant made this statement when trying to articulate the different social customs that existed between Atlantic Canada and the oil sands and how this might influence HIV/AIDS related risk behaviours.

Our data also suggested that social disruption occurred not just in northern Alberta but also in Atlantic Canada. Much of this disruption occurred due to lack of personal time when at home. One participant noted,

"I was out on the rigs for 15 days and I'd be off for six days. Six days seems nice but your first four days when you've been gone for half a month, you're doing your business, you're paying bills, you're running all over the place and the last two days you're gearing up to go again so there's not a lot of personal life either." 
In contrast to people who partied as a way of coping with the disruption of established social support networks other participants seemed to cope in more healthy ways through such activities as walking, reading, eating a healthy meal, engaging in self-talk about the job being temporary, and using the internet to communicate with people at home.

The concepts of social disruption and environment are related. Participants talked not only about how the social disruption influenced their health and but also about how the environment influenced them and their relationships.

\section{Environment}

Environment includes the built, natural, and social environments. Participants described the environment in a variety of ways suggesting that differences existed depending upon what company you worked for, whether you were located in work camps, private accommodations, or hotels. Generally, conditions were better in larger companies, and permanent well-established work camps. Participants agreed that most camp sites provided excellent food and many had good gym facilities. Extreme cold (with average winter temperature ranging at $-18 \mathrm{C}$ but on occasion dipping to as low as $-51 \mathrm{C}$ (Alberta Government, 2005), regularly put workers in danger of severe frostbite. Other health risks associated with the environment include geographic isolation from friends and family, dangerous travelling related to weather and road conditions, little leisure time, consistently working with the same small group of individuals, and short intervals off between shifts resulting in sleep deprivation. One individual described the stress associated with working with the same people consistently:

\footnotetext{
"Being with the same crew of guys ... they could be your best friends ... just five guys working together all the time and having the same days off ... you know you get stressed ... that took some getting used to ... But it's hard to get used to... the notion of being around the same guys all the time even when you're on your time off."
}

The social environment within the oil sands was also described by participants as violent. Violent episodes occurred both within the worksite and the wider community. To protect themselves participants talked about the need to be tough and maintain a macho image. One participant stated, "You got to be seen as a tough guy. If you don't, you won't survive ... what they'll do is, they'll gang up on you and they'll beat you up". Participants attributed increased violence to the culture that exists in Fort McMurray and surrounding areas. One participant noted "There's no warmth, there's no kindness, there's no sense of community". The need to maintain a macho image led to an increase in a number of potentially risky behaviours such as having multiple sexual partners and using the services of sex trade workers. One participant said, "I've had friends that have brought home STD's [sexually transmitted diseases] to their girlfriends". Another claimed, "If you left your boots outside your door, you'd get a discreet knock on the door .... some girl wanted to service you for a while". Still another made explicit the link between boomtown economies and STIs saying, "Money brings everything ... it brings prostitution, it brings disease". 


\section{Health services}

A consistent theme in the data was that if a migrant worker reported a health problem to a supervisor, $\mathrm{s} /$ he would arrange for visit to a health professional. This was particularly true for those living in work camps or working at remote sites where, according to one participant "If you have a health problem, you go to your supervisor; he'll get it looked at immediately". Not all workers accessed healthcare services while living in northern Alberta because "it might be more of a pain in the ass in terms of paper work so they would probably wait until they go home". Additionally, some participants noted that if they had an STI that needed treatment they would probably wait until returning home to seek treatment, due to time loss from work. This delay risks the health of the individual as well as anyone else with whom they have sexual contact.

One participant noted that education 'in regard to STIs or HIV prevention' was not easily available. Another participant did state, however, that in some camps, small mini stores sold condoms.

Participants reported drug testing (which could be construed as an occupational health and safety initiative) occurred frequently within the work environment. One participant noted he had been tested for drugs between 10 and 12 times in one year. To prevent usage, employers tested workers for drugs prior to employment and randomly. Drug testing was also standard procedure whenever an accident occurred. Migrant workers responded to these employer health regulations in several ways: Participants noted, "The best way to go is coke. It goes out of your system in three days. You can't trace it". Another individual claimed "a lot of people have gone from marijuana to using cocaine, crack cocaine ... it's only in your system for maybe a day or two". Some participants also commented that they used 'water pills' in to ensure drugs cleared the system as quickly as possible. Other participants noted that some workers packed 'flush kits' in their rig bag and used this material to help their body get rid of accumulated drugs quickly.

Drug use within the oil fields tended to differ depending upon an individual's living location. According to some participants much less drug use occurred in dry camps where alcohol was prohibited. However, one participant noted drug use in dry camps "was totally prohibited and totally, totally practiced. Cocaine is the candy of the oil-fields. Cocaine is everywhere". Another participant commented, "I walked in and there were two guys snorting coke off my bathroom counter". A third participant stated, "One guy was actually caught throwing the needles in his garbage and one of the girls stabbed herself and she reported it".

\section{Discussion}

This exploratory study increased our understanding of some lifestyle and social factors associated with increased risk taking behaviours that may lead to acquiring HIV or other health conditions, among people who move from Atlantic Canada to the oil sands in Northern Alberta. From the perspective of workers, migrating from Atlantic Canada to the oils sands in northern Alberta, social disruption and environmental influences, are factors that increase the risk-taking behaviour that may indirectly lead to acquiring HIV or other STIs. These risk-taking behaviours include taking drugs, taking more addictive drugs, and engaging in unsafe sexual practices. In addition, challenges associated with accessing health services may slow down treatment for STIs including HIV. 
Social disruption has also been shown to alter 'sense of community' (Park and Stokowski, 2009), ways of behaving, relationships, and attitudes (England and Albrecht, 1984). Our data are consistent with this literature and indicate that social disruption in northern Alberta has contributed to a partying culture, violence, drug use, casual or paid sex with multiple partners, alienation, and social disconnection. It appears that social disruption may occur in both home and host communities. This is consistent with the work of Ferguson (ND) who noted migratory workers experienced a strain on their family life and intimate relationships. This situation might be improved if focused health promotion and disease prevention programming could occur at each phase of migration (Zimmerman et al., 2011). These programmes could include a careful discussion about HIV prevention, prevalence of HIV and STIs in both the home and host community, information about the anticipated work situation and anticipatory guidance about the stressors the person may find upon returning home.

Issues related to the work environment and living arrangements also were prominent in our data. Drug use and violence were seen as everyday events. Employers tried to limit drug use with drug testing. On the surface, this would seem to help to eliminate drug use that could put people at risk for acquiring HIV or other STIs (as well as increase the safety of the work environment). What our study suggests, however, is that employers' drug testing policies may have unintended negative effects: First, it appears that the policy created a situation in which people shifted their drug of choice to one that clears the system faster, in this case the switch from marijuana to cocaine. Doing so, moved the workers from an arguably non-addictive to a known addictive drug and one that can be injected intravenously. Injection drug use is a key risk factor for HIV. Second, a drug testing policy appeared to contribute to covert drug use. When drug use is hidden this creates challenges for both drug users and service providers (Parker et al., 2012). For example, users may inadvertently harm themselves if they 'rush' while injecting creating abscesses or burns. It is critical that employers review drug-testing policies as this may be contributing to employees shifting their drug of choice to those with more potential for harm. However, it is also important to balance any policy decisions with the need to maintain a safe workplace.

One harm reduction initiative that could be put into place at the destination phase of migration includes the provision of crack pipes. This could help to eliminate transmission of HIV and other blood born pathogens that result from burns and cuts on the lips and mucous membranes that occur when people use homemade pipes from soda cans, straws, and bottles. For such an initiative to be successful both employees and employers as well as a variety of different health professionals would need to be involved. For example, in very small remote camps clean needles, condoms, and pipes might need to be provided whereas in camps closer to Fort McMurray this might not be necessary as local services may be accessed.

The need to maintain a macho image in order to protect oneself from violence seemed to be an accepted part of the environment. It may be that in order to appeal to this 'macho image' and make it acceptable to participate in HIV/AIDS prevention activities specific educational and outreach materials may be required. These initiatives may be more acceptable if they are offered online as this would help to maintain privacy within this environment. The Alberta Government's 'Plenty of Syph' campaign is an example of such an initiative (Alberta Health Services, 2011).

Access to health services, visibility of health promotion campaigns and harm reduction programmes varied depending upon the mobile workers' work sites. One 
participant noted the practice of going through one's supervisor to access healthcare often meant health problems were untreated until arriving back at home particularly if the individual did not want the supervisor to know about the particular problem. Employers may take an upstream approach to HIV/STI prevention by working with the health sector to ensure health services more are more easily accessible. In addition, employers may have to change their policies so that employees who access these services are paid for the work time they miss.

\section{Study strengths and limitations}

A major strength of this study was that the semi-structured interview schedule allowed enough flexibility to explore topics that were initially unfamiliar to the research team. In addition, theoretical sampling allowed us to access participants with knowledge about certain themes that were emerging in our data.

A limitation of this study is that all interviews were carried out in Eastern Canada while participants were in their home communities. Different themes may have emerged had some of the interviews been conducted in northern Alberta at the work or campsite. However, conducting on-site interviews may be difficult to arrange as it requires participants to take time off work which negatively affects their income. In order to overcome this challenge it would be beneficial to partner with industry in future research so that participants did not experience any financial cost for participating.

A second limitation is that one of the ethics committees that reviewed the research proposal requested that we ask all participants to speak in second person if describing behaviours that could potentially be considered illegal. This may have limited the types of information participants shared with us.

Our research is consistent with qualitative methods, therefore, there was no attempt to obtain a representative sample, to test theory or advance generalisable statements. Our research cannot be generalised but can be used as the basis for action, pilot interventions and/or further research.

\section{Recommendations}

More research related to HIV/AIDS and STIs prevention within the oil sands is required prior to making recommendations to influence policy. Future research could include case studies, ethnographic, or mixed methods research that would have an observational component. These studies should include employees, employers, and healthcare workers. This would enrich our understanding of complex social and structural factors that may influence the spread of HIV/AIDS and other communicable diseases. Observational studies may be particularity useful as recurring patterns of behaviour and structural elements influencing the spread of HIV/AIDS that are difficult to articulate, may be identified through this approach. In considering future research projects partnerships between public health and industry need to be explored as these joint partnerships may help to improve 'uptake' of research findings. 


\section{Conclusions}

We used qualitative research to explore the perceptions of mobile workers. We asked participants about how mobility influenced health risks including exposure to HIV and STIs. These mobile workers experienced social disruption and were working in environments that led to high-risk behaviours. Additionally, they sometimes experienced barriers to accessing health services. Policy makers, both employers and public health officials, should consider a variety of harm reduction, health promotion, and safety initiatives that promote the well-being of workers and a safe work place, thus, minimising the potential risk of HIV/AIDS and STIs to workers and partners in home and host communities.

\section{References}

Alberta Government (2005) Climate Data [online] http://www3.gov.ab.ca/env/water/GWSW/quantity/learn/what/CLM_climate/CLM1_metdata. html (accessed 7 July 2013).

Alberta Health Services (2011) Plenty of Syph [online] http://www.nccid.ca/files/Partner_Notification/2011_Consultation/AB_syph_campaign_Karen .pdf (accessed 7 July 2013).

Athabasca Regional Issues Working Group (2007) Report on Mobile Workers in the Wood Buffalo Region of Alberta, Nichols Applied Management, Edmonton.

Canadian Institutes of Health Research (2011) About the Canadian HIV/AIDS Community-Based Research Program [online] http://www.cihr-irsc.gc.ca/e/40943.html\#d1 (accessed 7 July 2013).

Davies, A. et al. (2010) 'Migration: a social determinant of the migrants' health', Euro Health, Vol. 16, No. 1, pp.10-12.

Department of Health and Community Services (2010) Number of New HIV Cases, by Year, Sex and Risk Factor, Newfoundland and Labrador, 1984-2010 [online] http://www.health.gov.nl.ca/health/publichealth/cdc/fs_hiv_aids_1984_2010.pdf (accessed 7 July 2013).

Dodson, B. and Crush, J. (2006) 'Deadly links between mobility and HIV/AIDS', Crossings, Vol. 7, No. 1, pp.1-12.

Dolan, A. et al. (2005) 'Restructuring health in costal rural communities', Ecohealth, Vol. 2, No. 3, pp.195-208.

England, J. and Albrecth, S. (1984) 'Boomtowns and social disruption', Rural Sociology, Vol. 49, No. 2, pp.230-246.

Ferguson, N. (n.d.) 'From coal pits to tar sands: labour migration between an Atlantic Canadian region and the Athabasca oil sands', Just Labour: A Canadian Journal of Work and Society, Vols. 17/18 [online] http://www.justlabour.yorku.ca/volume17/pdfs/08_ferguson press.pdf (accessed 7 July 2013).

Goldenberg, S. et al. (2008) 'Barriers to STI testing among youth in a Canadian oil and gas company', Health \& Place, Vol. 14, No. 4, pp.718-729.

Government of Alberta (1995-2012) Facts and Statistics [online] http://www.energy.gov.ab.ca/OilSanda/791.asp (accessed 7 July 2013).

Government of Alberta (2011) Alberta Sexually Transmitted Infections and Blood Borne Pathogens 2011-2016 [online] http://www.health.alberta.ca/documents/STI-BBP-Plan-2011.pdf (accessed 7 July 2013).

Gushulak, B. and MacPherson, D. (2011) 'Health aspects of the pre-departure phase of migration', PLoS Medicine, Vol. 8, No. 5, pp.1-7. 
Health Canada (2006) Health Canada's Northern Gas Project Secretariat, Health Canada's written intervention for the Mackenzie Gas Project environment assessment: Presented to the Joint Review Panel, January 2006, Ottawa, ON.

Mendola, M. (2006) Rural-Out Migration and Economic Development at Origin: What Do We Know?, University of Sussex, Sussex.

Merriam, S. and Simpson, E. (2000) A Guide to Research for Educators and Trainers of Adults, 2nd ed., Krieger, Florida.

Office of the Chief Medical Officer of Health (2011) Epidemiology of HIV and AIDS in New Brunswick, Fredericton, NB.

Park, M. and Stokowski, P. (2009) 'Social disruption theory and crime in rural communities: comparisons across three levels of tourism growth', Tourism Management, Vol. 30, pp.905-915, doi: 10.1016/j.tourman.2008.11.015.

Parker, J. et al. (2012) 'Access to harm reduction services in Atlantic Canada: implications for non-urban resident who inject drugs', Health \& Place, Vol. 18, No. 2, pp.152-162.

Polit, D. and Beck, C. (2009) Essentials of Nursing Research: Appraising Evidence for Nursing Practice, Lippincott, Williams, and Wilkins, Philadelphia.

Public Health Agency of Canada (2008) HIV and AIDS in Canada: Surveillance Report to December 31, 2007, Public Health Agency of Canada, Ottawa.

Quinn, T. (1994) 'Population migration and the spread of types 1 and 2 human immunodeficiency viruses', Proc. Natl. Acad. Sci., Vol. 91, pp.2407-2414.

Saggurti, N. et al. (2009) 'Migration, mobility and sexual risk behavior in Mumbai, India', AIDS and Behavior, October, Vol. 15, No. 5, pp.921-927.

Saggurti, N. et al. (2008) 'HIV risk behaviours among contracted and non-contracted male migrant workers in India: potential role of labour contractors and contractual systems in HIV prevention', AIDS, Vol. 22, No. 5, pp.S1-S10.

Sandelowski, M. (2000) 'Focus on research methods: whatever happened to qualitative description?', Research in Nursing and Health, Vol. 23, No. 4, pp.334-340.

Skeldon, R. (2000) Population Mobility and HIV Vulnerability in South East Asia: An Assessment and Analysis [online] http://siteresources.worldbank.org/INTTSR/Resources/ 462613-1135099994537/Mobilitypaper.pdf (accessed 7 July 2013).

Statistics Canada (2010) Canada's Population Estimates [online] http://www.statcan.gc.ca/daily-quotidien/110622/t1 10622a2-eng.htm (Accessed 7 July 2013).

Statistics Canada (2011) The Daily, 24 March 2011 [online] http://www.statcan.gc.ca/ daily-quotidien/110324/dq110324b-eng.htm (accessed 7 July 2013).

Summers, G. and Branch, K. (1984) 'Economic development and community social change', Annual Review of Sociology, Vol. 10, pp.141-166.

Thorne, S. (2008) Interpretative Description, Left Coast Press, Walnut Creek, CA.

UNAIDS (2008) Policy Brief: HIV and International Labour Migration [online] http://data.unaids.org/pub/Manual/2008/jc1513a_policybrief_en.pdf (accessed 8 July 2013).

Zimmerman, C. et al. (2011) 'Migration and health: a framework for 21st century policy-making', PLoS Medicine, Vol. 8, No. 5, pp.1-7. 